\title{
Sucessão de empregadores e as privatizações
}

\author{
Cristiano Brito Lins Costa ${ }^{1}$ \\ Prof. Dr. Lourival José de Oliveira ${ }^{2}$
}

\section{Resumo}

\begin{abstract}
Analisou-se a sucessão de empregadores e as privatizações, assunto sobre o qual recai algumas divergências jurisprudenciais e incertezas doutrinárias. Definiu-se contrato de trabalho e ao adentrar nesta problemática conceituou-se empregados, empregadores, relacionado a este último delimitou-se o que seria o estabelecimento comercial e ainda, realçou-se qual a natureza jurídica do contrato de trabalho. Foi pesquisado sobre a sucessão de empregadores, assim apresentou-se o seu conceito, sua natureza jurídica e suas características e ainda, sobre tal instituto esmiuçou-se a questão das responsabilidades do sucessor e do sucedido e por fim, trabalhou-se acerca da validade das cláusulas contratuais que definem responsabilidade entre sucessor e sucedido quando aos débitos trabalhistas. Ao estudar a problemática sobre as privatizações e instituto justrabalhista em estudo, previamente conceituou-se contratados administrativos e demonstrou-se a sua natureza jurídica e também apresentouse breve análise sobre licitações. Entrando na análise das privatizações apresentou-se o seu contexto histórico, definiu-se tal procedimento, pesquisouse sobre o processo em que esta se desenvolve e estudou-se a questão das cláusulas limitadoras de responsabilidade inseridas nos contratos entre o poder público e particulares.
\end{abstract}

Palavras-Chave: Contrato de trabalho; Sucessão de empregadores; Sucessão e privatizações; Cláusulas limitadores de sucessão; Responsabilidade do sucessor; Responsabilidade do sucedido.

\section{Introdução}

O instituto do Direito do Trabalho objeto do presente estudo, Sucessão de Empregadores, é de suma importância, pois seu fim se coaduna com o fim último do próprio Direito Laboral, qual seja, dar maior proteção aos trabalhadores, os quais se mostram indiscutivelmente hipossuficientes frente ao poder econômico dos empregadores, situação esta que é o fundamento do Direito do Trabalho.

Acadêmico do 5o ano matutino do curso de Direito da Universidade Estadual de Londrina.

Doutor em Direito (PUC-SP); professor adjunto da Universidade Estadual de Londrina; professor da UNOPAR; professor da FACCAR; professor da UNIMAR. 
Nos dias atuais, em razão do grande dinamismo que se vê no mundo empresarial, tornam-se cada vez mais comuns grandes mudanças nas empresas, como, alienação, mudança da titularidade da empresa, transferência de bens ou ainda mudanças em sua estrutura jurídica.

Daí surgem algumas dúvidas como, contra quem o empregado deve pleitear seus direitos, contra o antigo empregador que foi quem deu início à relação de emprego, ou, contra o novo proprietário que veio a substituir o antigo. Se o novo proprietário for responsabilizado, resta também a indagação sobre a abrangência de sua responsabilidade, pois é importante saber se ele será responsável pelos créditos dos empregados, constituídos antes ou depois da transferência da empresa. E ainda como fica o direito daqueles empregados que trabalhavam para a empresa transferida e têm créditos a pleitear, mas não passaram a trabalhar para a 'nova' empresa? Quem responderá por seus créditos, o antigo empregador ou o novo titular da empresa, para quem nunca trabalharam?

E ainda relacionado a temática tem-se as privatizações, as quais se mostram presentes, e se poderia dizer, ainda que, de forma intensa, pois o país desenvolveu até mesmo um Programa Nacional de Desestatização.

Diante de tal questão, como ficam os direitos dos trabalhadores quando pelo processo de privatização (ou desestatização) o poder público transfere para o setor privado atividade econômica por ele antes desenvolvida?

É importante saber se do processo de privatização decorre o fenômeno da sucessão de empregadores, e ainda, se em tais processos é comum o poder público instituir que os eventuais débitos trabalhistas serão suportados por ele, o que é feito para que aumente o interesse do setor privado pela aquela atividade que se visa transferir. Assim, em caso de eventual sucessão, o que prevaleceria são as normas do Direito do Trabalho ou suposto interesse público por uma contratação mais vantajosa com o setor privado. 


\section{Contrato de trabalho}

\subsection{Conceito}

De início é importante destacar a existência de uma definição legal de contrato de trabalho, a qual vem expressa no artigo 442 da CLT, o citado dispositivo diz que o contrato individual de trabalho corresponde à relação de emprego.

Pode-se afirmar que o contrato de trabalho-emprego é o acordo firmado entre duas partes, o qual tem como objeto a compra de força de trabalho, mas com uma peculiaridade, tal força deve ser exercida com a observância dos elementos inerentes à relação de emprego.

Neste contexto frisa-se o conceito de contrato de trabalho segundo Octavio Bueno Magano (1998, p. 18): “O seu conceito é o de negócio jurídico pelo qual uma pessoa física se obriga, mediante remuneração, a prestar serviços não eventuais a outra pessoa ou entidade, sob a direção de qualquer das últimas".

O doutrinador José Martins Catharino (1982, p. 218) faz critica a denominação dada ao instituto, pois considera que "o termo mais correto a ser utilizado deveria ser contrato de emprego e relação de emprego, porque não será tratada da relação de qualquer trabalhador, mas do pacto entre o empregador e o empregado, do trabalho subordinado".

\subsection{Empregado}

Antes de tecer qualquer comentário com o fim de definir empregado, deve ser destacada a definição legal do instituto, a qual vem disposta no artigo $3^{\circ}$ da CLT: “Considerase empregado toda pessoa física que prestar serviços de natureza não eventual a empregador, sob a dependência deste e mediante salário".

A par de tal conceito dá-se a oportunidade de visualizar que, antes de tudo, a legislação trabalhista visa tutelar a pessoa física do trabalhador, neste passo os serviços prestados por pessoas jurídicas fogem, portanto, da seara trabalhista, pois são regidos pelo Direito Civil.

Após a definição legal importante se mostra à adotada por Maurício Godinho Delgado (2001, p. 347): “Empregado é toda pessoa natural que contrate, tácita ou 
expressamente, a prestação de seus serviços a um tomador, a este efetuados com pessoalidade, onerosidade, não-eventualidade e subordinação".

É de grande relevância esmiuçar as características trazidas pelo texto da lei:

"Não eventual", significa dizer que o contrato de emprego é um contrato de trato sucessivo, ou seja, o trabalho deve ser de natureza contínua, com habitualidade. $\mathrm{O}$ trabalho eventual seria aquele sem qualquer regularidade, prestado esporadicamente.

Sobre a dependência, coaduna-se com o entendimento do doutrinador Sérgio Pinto Martins (2002, p. 138), quando afirma que o termo trazido pela norma não é o mais adequado, sendo melhor utilizar subordinação, que seria o estado de sujeição em que se coloca o empregado em relação ao empregador, aguardando ou executando as ordens deste. Tal subordinação é jurídica, pois emana do contrato de trabalho. Na subordinação a prestação do trabalho não se dá com liberdade por parte do empregado, pois o mesmo fica restrito aos comandos do empregador, situação que decorre do chamado poder diretivo do empregador, neste sentido é o entendimento de Francisco Ferreira Jorge Neto (2001, p. 53).

No tocante ao salário, pode-se afirmar ser este da natureza da relação, afinal o contrato de trabalho é eminentemente oneroso, não existindo contrato gratuito. $\mathrm{O}$ trabalhador/empregado presta serviços com o intuito de receber uma contraprestação pecuniária, o salário.

Além dos requisitos trazidos pelo artigo supra transcrito ainda pode ser trazido para o presente trabalho o que é extraído da definição legal de empregador, a qual vem disposta no artigo $2^{\circ}$ da Consolidação das Leis do Trabalho, quando a norma diz o empregador "assalaria e dirige a prestação pessoal de serviços".

Esse artigo exige que exista a pessoalidade na relação de emprego, pois o contrato de emprego é "intuitu personae", em atenção a tal requisito é dever destacar que o empregado não pode transferir suas obrigações a terceiros, assim os serviços devem ser prestados necessariamente por ele, diretamente, conforme ensina Francisco Ferreira Jorge Neto (2001, p. 50).

Elege-se o conceito trazido por Octavio Bueno Magano (1998, p. 23), o qual é, ao mesmo tempo, o mais simples e didático, pois segundo o doutrinador em razão de o empregado ser um dos sujeitos do contrato de trabalho, sua fisionomia será indicada pelas características inerentes a tal contrato. 


\subsection{Empregador}

O artigo $2^{\circ}$ da CLT traz a definição legal de empregador, o qual abaixo se transcreve em face de sua grande importância para a análise do presente tema:

Art. $2^{\circ}$ - Considera-se empregador a empresa individual ou coletiva, que, assumido os riscos da atividade econômica, admite, assalaria e dirige a prestação pessoal de serviços.

$\S 1^{\circ}$ Equiparam-se ao empregador, para os efeitos exclusivos de relação de emprego, os profissionais liberais, as instituições de beneficência, as associações recreativas ou outras instituições sem fins lucrativos, que admitirem trabalhadores como empregados.

Diante o citado artigo observa-se a definição de Maurício Godinho Delgado (2001, p. 389) "Empregador define-se como a pessoa física, jurídica ou ente despersonificado que contrate a uma pessoa física a prestação de serviços efetuados com pessoalidade, onerosidade, não eventualidade e sob sua subordinação".

Com relação ao termo empresa trazido pela definição legal relevante se faz a relação existente entre os conceitos de empregador e empresa, segundo Amauri Mascaro Nascimento (2001, p. 603), os conceitos guardam relação de gênero e espécie, assim, devido à amplitude do conceito de empregador, o mesmo termina abrangendo o de empresa.

O doutrinador Amauri Mascaro Nascimento (2001, p. 602) traz entendimento que serve para fechar o tema em face de sua simplicidade, segundo ele "é por meio da figura do empregado que se chegará à do empregador, independentemente da estrutura jurídica que tiver". Tal conceito assevera sua importância por que ressalta que todo aquele que toma serviços de pessoa física e com a presença dos elementos inerentes à figura do empregado será empregador, ou seja, empregador é aquele que tem empregado, por mais simplório que parece a conclusão ela é a que melhor define a figura do empregador.

\subsection{Natureza jurídica do contrato de emprego}

É importante que se esclareça qual é a natureza jurídica do contrato travado entre empregado e empregador.

Neste sentido, apura-se que, a destacada relação é vista como uma obrigação de fazer, na qual existe uma forma específica de ser prestada, pois para que se configure devem 
estar presentes os cinco elementos inerentes à relação de emprego. Assim, tem-se que a forma de prestação será o diferencial desta relação contratual para com as demais.

\section{Sucessão de empregadores}

\subsection{Conceito}

Começando a análise da sucessão de empregadores julga-se de inegável relevância a lição de Evaristo de Moraes Filho (apud PINTO, 1978, p. 227), a qual explica a razão do nome dado ao instituto que se irá estudar, citado doutrinador afirma que "não se trata de sucessão de empresa, mas sucessão de empregadores, pois o empregador nem sempre é a empresa, mas pode ser a pessoa física".

O instituto sobre estudo vem regulado pelos artigos 10 e 448 da CLT, os quais merecem serem transcritos:

Artigo 10 - Qualquer alteração na estrutura jurídica da empresa não afetará os direitos adquiridos por seus empregados.

Artigo 448 - A mudança na propriedade ou na estrutura jurídica da empresa não afetará os contratos de trabalho dos respectivos empregados.

Relevante se mostra o conceito atribuído por Maurício Godinho Delgado (2001, p. 406) em sua obra: "Consiste no instituto jus-trabalhista em virtude do qual se opera, no contexto da transferência de titularidade de empresa ou estabelecimento, uma completa transmissão de crédito e assunção de dívidas trabalhistas entre alienante e adquirente envolvidos".

Assim, tem-se que, com a alienação ou cessão (ou ainda, fusão e cisão) da empresa ou do estabelecimento o adquirente se investirá na posição do antigo proprietário, ou seja, ele assumirá todos os créditos e débitos. Segundo Gustavo Felipe Barbosa Neto (2007, p $160)$ "ocorrendo a sucessão trabalhista o sucessor responde por todos os direitos trabalhista do empregado, ainda que referentes a período anterior à sucessão, e mesmo que o contrato de trabalho tenha cessado anteriormente a ela".

Sérgio Pinto Martins (2006, p. 62) afirma em sua obra que "vincula-se o empregado ao empreendimento e não à pessoa física dos sócios que o compõem”. 
Lembra-se também os apontamentos trazidos por Amauri Mascaro Nascimento (2001, p. 680), para quem, "Os contratos de trabalho são mantidos com a organização de trabalho e não com as pessoas que estejam eventualmente à frente dessa mesma organização".

Portanto, se vê que na sucessão transferem-se os créditos dos trabalhadores junto com a atividade econômica organizada.

\subsection{Natureza jurídica}

Muitos doutrinadores tentam equiparar o instituto a outros pertencentes ao Direito Civil como a novação, sub-rogação, delegação e estipulação em favor de terceiros. Assim deve ser lembrado que os dois primeiros são descartados, porque dependem da autonomia da vontade, o último também não pode ser aceito, pois tem em sua essência trazer benefícios ao terceiro, o que não condiz com o presente instituto. Com relação às tentativas de equiparação do instituto a outros do Direito Civil Maurício Godinho Delgado (2001, p. 423) é enfático, "qualquer dessas figuras civilistas não se ajusta satisfatoriamente à sucessão trabalhista".

Diante do exposto, se acompanha as lições de Maurício Godinho Delgado (1982, p. 147) o qual defende que o instituto sob exame tem natureza jurídica própria, assim entende que "consiste a figura justrabalhista na conjugação de duas operações distintas, mas combinadas - transmissão de crédito e assunção de dívidas - que se realizam ambas, no mesmo momento, em decorrência da lei ope legis", tal entendimento é feito baseando-se nas lições do jurista José Martins Catharino.

Aponta-se, portanto, que a instituto sob estudo não se adequa a natureza de qualquer dos institutos provenientes do Direito Civil, se analisados isoladamente, mas podese concluir que a sucessão possui características somadas de institutos diferentes, fato que denota a sua natureza própria.

\subsection{Características}

Importante destacar as características do instituto para uma melhor compreensão do mesmo. 
Neste sentido, se traz a lição de Délio Maranhão (2004, p. 305) que afirma, "para que ocorra a sucessão, não é preciso que uma empresa desapareça e outra ocupe o seu lugar", e ainda completa, "para que exista a sucessão de empregadores, dois são os requisitos indispensáveis. a) que um estabelecimento, como unidade econômico-jurídica, passe de um para outro titular; b) que a prestação de serviço pelos empregados não sofra solução de continuidade".

Sobre a transferência do estabelecimento Maurício Godinho Delgado (2001, p. 411) afirma:

Há sucessão de empregadores, na acepção celetista, não ocorre somente com o transpasse de toda a organização, mas também com a transferência de apenas uma ou algumas de suas frações (estabelecimentos): nas duas hipóteses, altera-se, subjetivamente, o contrato, ingressando, no pólo passivo, novo titular.

Outra característica importante é a proteção dos créditos trabalhista, já que em virtude das disposições legais ora estudadas extrai-se que os créditos seguem o estabelecimento, estrutura econômico-produtiva.

Para Francisco Ferreira Jorge Neto $(2001$, p. 117) “O pressuposto da sucessão é a alienação de uma organização produtiva de um titular para outro, logo o que se tem em questão é a transferência de uma universalidade".

Diante das considerações trazidas acima resta claro que o Direito do Trabalho visa vincular os créditos dos trabalhadores ao complexo de bens que é necessário para a viabilização da atividade econômica exercida pela empresa.

\subsection{Responsabilidade do sucessor e sucedido}

Evaristo de Moraes (apud BARROS, 1960, p. 254) acerca do responsabilização, para quem fica o sucessor "inteiramente responsável por todos os direitos adquiridos durante a vigência anterior do contrato. Mesmo para os já rescindidos pelo antigo empregador, inexistente no momento do trespasse, fica privativamente responsável o sucessor".

Relacionado ao tema destaca-se o entendimento de Maurício Godinho Delgado (2001, p. 418), para quem: 
A figura sucessória trabalhista provoca a automática transferência de direitos e obrigações contratuais, por força de lei, do antigo titular do empreendimento para o novo titular, ou seja, do antigo empregador para seu sucessor.

O mesmo doutrinador, mas agora no tocante a responsabilidade do sucedido, afirma que "como regra geral, não preserva, em princípio, qualquer responsabilidade (solidária ou subsidiária) do alienante pelos créditos trabalhistas relativos ao período anterior à transferência" (DELGADO, 2001, p.420).

Francisco Ferreira Jorge Neto $(1985$, p. 52) ainda acentua o entendimento de Mozart Victor Russomano, para quem, "[...] desde que se demonstre fraude ou simulação e desde que o empregado possa provar, satisfatoriamente, a má situação financeira do novo empregador, é de se admitir que ele reaja contra a nova ordem das coisas".

Por sua vez Amauri Mascaro Nascimento (2001, p. 685) defende que a responsabilidade existente entre sucessor e sucedido deveria ser solidária, situação que aumentaria a proteção dos trabalhadores, principalmente em casos de o sucessor não ter condições de responder pelos contratos de trabalho e créditos. Tais críticas só podem ser consideradas construtivas, pois vão ao encontro do objetivo principal do instituto que é o de trazer maiores garantias acerca dos créditos dos trabalhadores.

Importante se frisar que eventual imputação de responsabilidade ao sucedido deve ser na forma subsidiária, a final a solidariedade não pode ser presumida, deve ser advinda de convenção ou de lei.

\subsubsection{Validade e eficácia de cláusulas contratuais definindo responsabilidades}

É muito comum que nos contratos de alienação de 'empresas' os contraentes estipulem cláusulas com o fim de delimitar as responsabilidades de cada um com relação aos débitos trabalhistas. Em face de tal praxe traz-se o entendimento da doutrina trabalhista com relação a ela. Neste diapasão, tem-se que "tais cláusulas restritivas da responsabilização trabalhista não têm qualquer valor para o Direito do Trabalho" (DELGADO, 2001, p.419).

Neste sentido se destaca a lição de Francisco Ferreira Jorge Neto (2001, p. 126):

A doutrina é unânime em afirmar que a referida cláusula não possui a menor relevância para o Direito do Trabalho. A imperatividade dos arts. 10 e 448 da CLT é patente, pois estabelecem regras que não podem ser postas de lado pela vontade 
das partes (sucessor e sucedido) quando da assinatura do ato jurídico que estabelece a alienação da empresa.

Aufere-se assim que as cláusulas contratuais que preceituam a limitação de responsabilidade quando aos débitos trabalhistas são plenamente válidas, mas somente entre as partes e no âmbito da relação travada entre elas. Assim, por exemplo, o contrato de compra e venda de uma empresa, vai obrigar o adquirente e o alienante, de forma que a relação entre eles esta relacionada ao direito civil, pois decorre de um contrato cível, assim a está área será restrito não tendo eficácia alguma na seara trabalhista. Situação que não poderia ser diversa, afinal a sucessão é decorrente de norma de ordem pública, a qual evidentemente deve se sobrepor as disposições de eminente natureza contratual, que prevêem a limitação de responsabilidades, as quais só fazem lei entre as parte.

\section{Efeitos dos contratos administrativos de privatizações}

\subsection{Dos contratos administrativos}

\subsubsection{Licitação}

Importante se faz tratar da chamada Licitação, antes de analisar os contratos administrativos, isto se dá pelo fato de aquela ser o procedimento preliminar adotado pelo Poder Público antes de adquirir, alienar, locar bens e contratar a execução de obras ou serviços.

Para Celso Antônio Bandeira de Mello (2005, p. 491) licitação “é um certame que as entidades governamentais devem promover e no qual abrem disputa entre os interessados em com elas travar determinadas relações de conteúdo patrimonial, para escolher a proposta mais vantajosa às conveniências públicas". O autor ainda destaca que "tal procedimento tem previsão na Carta Magna, em seu artigo 37, inciso XXI".

Destaca-se, ainda, que o procedimento licitatório possui uma dupla função. Em primeiro lugar dar a todos os que se interessarem a oportunidade de disputar pela possibilidade de firmar um contrato junto a administração pública, e ainda, buscar dentre os interessados o que melhor se adequa aos interesses da administração. 


\subsubsection{Natureza jurídica dos contratos administrativos}

Antes de auferir a natureza propriamente dita dos contratos administrativos, é importante trazer um conceito do que seria contrato administrativo. Neste sentido, destacase o conceito atribuído pelo professor Celso Antônio Bandeira de Mello (2005, p. 581):

É um tipo de avença traçada entre a Administração e terceiros na qual, por força de lei, de cláusulas pactuadas ou do tipo do objeto, a permanência do vínculo e as condições preestabelecidas assujeitam-se a cambiáveis imposições de interesse público, ressalvados os interesses patrimoniais do contratante privado.

Nota-se que o contrato administrativo é uma espécie do gênero contrato, o qual não tem conceituação específica do direito privado, e sim da teoria geral do direito.

Portanto, os contratos administrativos têm inegavelmente as características básicas dos contratos, conforme ensina Maria Sylvia Zanella Di Pietro (2004, p. 244) é um "acordo de vontades gerador de direitos e obrigações recíprocas".

\subsection{Das privatizações}

\subsubsection{Conceito de privatizações}

Com o intuito de melhor compreender o tema que se visa abordar no presente capítulo de suma importância se mostra trazer inicialmente uma conceituação do que seria privatização.

Para Cristiane Derani (2002, p. 110) significa “[...] transferência de um serviço realizado pelo poder público para o poder privado e também à transferência da propriedade de bens de produção públicos para o agente econômico privado".

E ainda no entender de Toshio Mukai (2002, p. 83), "privatizar significa transferir para a iniciativa privada não só o serviço público, mas também a própria empresa estatal que até então o preste". 


\subsubsection{Do processo de privatização}

As privatização precedem uma licitação, processo este que é regulado pela Lei $n$. 8.666/93. Da análise inicial de tal lei já se poderia concluir que a modalidade a ser aplicada seria a da 'concorrência', prevista no artigo 20 da citada Lei.

No entanto a Lei $9.491 / 97$, trouxe no seu artigo $4^{\circ}$, nos seus incisos as modalidades operacionais das chamadas desestatizações, e ainda é importante ser frisado a redação do parágrafo $3^{\circ}$ : "Nas desestatizações executadas mediante as modalidades operacionais previstas nos incisos I, IV, V e VI deste artigo, a licitação poderá ser realizada na modalidade de leilão".

Assim a Lei 9.491/97 trouxe uma nova face para o procedimento conhecido como leilão, para que o mesmo pudesse ser aplicado no programa de desestatização.

Neste sentido se fazem importantes os apontamentos de Hely Lopes Meirelles (2000, p. 314-315), para quem:

O leilão, portanto, assumiu outra dimensão como procedimento licitatório. Nestes casos, deverá ser exigido qualificação de todos os interessados e os demais elementos considerados indispensáveis para o êxito da operação, inclusive a prestação de garantia. Os leilões ocorridos dentro do Programa Nacional de Desestatização têm sido realizados nas Bolsa de Valores, com habilitação prévia dos interessados e garantia da proposta, variando os requisitos técnicos, financeiros e operacionais exigidos, conforme o objeto licitado.

Com o mesmo entendimento acerca do leilão no PND é a lição trazida por Lúcia Valle Figueiredo (2004, p. 469) em sua obra, para quem:

Atualmente, todas as privatizações se fazem por leilão, quando deve ser verificada inicialmente, dado o porte dos empreendimentos que vêm sendo transferidos ao setor privado, a capacidade técnica e econômica dos possíveis licitantes. Na hora do leilão, a abertura dos envelopes dirá respeito ao preço pago.

\subsection{Dos efeitos das cláusulas impeditivas da sucessão de empregadores}

Após os apontamentos feitos com relação às privatizações e os contratos administrativos, importante tratar agora da relação de tais institutos com a sucessão de empregadores. 
Para isto destaca-se o entendimento de Francisco Ferreira Jorge Neto (2001, p. 157), para quem, o instituto da sucessão está necessariamente relacionado com as privatizações, isto se dá pelo fato de que a mesma tem como principal característica a transferência de titularidade de uma atividade econômica, a qual passará de um titular público para um privado.

Seguindo a linha de raciocínio Francisco Ferreira Jorge Neto (2001, p. 157) entende que:

\begin{abstract}
A transferência dos ativos da esfera pública para o setor privado, com a mudança na titularidade ou alteração na estrutura jurídica das empresas estatais, prosseguindo-se a atividade econômica organizada, com a utilização da força de trabalho, evidencia a responsabilidade do sucessor pelos contratos de trabalho dos empregados (arts. 10 e 448, CLT).
\end{abstract}

Tem-se então que as privatizações nada mais são do que a mudança de titularidade de uma atividade econômica, com a especificidade de a transferência se dar de um ente público para um privado, assim tal mudança não deve influir sobre os contratos de trabalho, conforme se extrai da análise do instituto da sucessão, de tal forma que Francisco Ferreira Jorge Neto (2001, p. 158) é categórico ao tratar da responsabilidade do sucessor privado, dizendo que "a responsabilidade envolve os débitos trabalhista passados e futuros".

A Lei n. 9.491/97 (trata do PDN), a qual não traz qualquer menção acerca da responsabilidade do sucessor pelos débitos trabalhistas. Assim, vê-se que eventual disposição neste sentido é encontrada no contrato que efetiva a privatização, portanto, uma avença contratual, a qual faz lei entre as partes, gerando direitos e obrigações recíprocas. Os trabalhadores não participam de tal acordo, visto isto, tais disposições não podem influir em seus direitos, principalmente porque tais direitos são embasados em normas de ordem pública, as quais obviamente se sobrepõem aos contratos.

Ainda não se poderia aceitar a tese de que as privatizações se dão por interesse público, devendo assim prevalecer sobre as normas trabalhistas, afinal a legislação trabalhista sempre foi expressa no sentido de caracterização da sucessão. E mesmo diante disto a Lei do PND, muito mais recente, não trouxe qualquer dispositivo sobre o tema, tornando-se imperativo concluir que não era a intenção do legislador afastar o instituto da sucessão das privatizações. Situação diversa é vista na Lei n. 11.101/2005 (Lei de falência e 
recuperação judicial e extrajudicial de empresas), a qual tem disposição expressa no sentido de afastar a sucessão trabalhista, conforme artigo 141, inciso II, da citada Lei.

Por fim, fecha-se o presente capítulo juntamente com os ensinamentos trazidos por Francisco Ferreira Jorge Neto (2001, p. 160), para quem, a responsabilidade do sucessor determinada pelo artigo 10 e 448 da CLT é com relação aos contratos rescindidos antes da sucessão e os que prosseguem com a empresa privatizada, e o autor ainda conclui que "as normas consolidadas são dispositivos de ordem pública, inarredáveis e inderrogáveis pela vontade das partes (sucessor e sucedido)".

\section{Conclusão}

Demonstrou-se no presente trabalho, que o estabelecimento comercial é um complexo de bens corpóreos e incorpóreos, necessários ao desenvolvimento de uma determinada atividade econômica. Deixou-se claro que tal complexo de bens, também chamado de unidade econômico-produtiva, está diretamente ligada aos trabalhadores e principalmente aos seus direitos.

Conceituou-se que a sucessão de empregadores é o instituto onde, em virtude de lei, transfere-se ao adquirente de uma atividade econômica, ou de parte dela, a responsabilidade sobre os débitos trabalhista.

Estabeleceu-se que o instituto da sucessão tem natureza jurídica própria, de forma que se mostra infrutífera a tentativa de grande parte da doutrina especializa de adequá-lo a algum instituto proveniente do Direito Civil. Na verdade, a sucessão mostra-se como a soma de características de mais de um instituto civilista. Assim, é uma cessão de créditos e assunção de débitos, mas ainda com certa peculiaridade, pois independe da vontade das partes e se dá por expressa determinação legal.

A sucessão tem como características, positivar a intangibilidade dos contratos de trabalho frente às mudanças sofridas pela empresa. Assim, mesmo com a alienação de uma empresa ou se uma unidade econômico-jurídica, os contratos permanecem inalterados e consequentemente os direitos dos trabalhadores.

Foi visto que a continuidade da prestação de serviços pelo empregado para o 'novo empregador' - sucessor, não é essencial à caracterização da sucessão, mas a presença de tal continuidade demonstra de forma inquestionável a sucessão de empregadores. 
Atribuiu-se como característica da sucessão, o aumento das garantias dos créditos dos trabalhadores, pois em decorrência de tal instituto, tais créditos são vinculados à unidade econômico-produtiva da empresa, razão pela qual eles a seguem.

Restou estabelecido que não interessa para o Direito do Trabalho o como se dá a transferência da empresa ou estabelecimento, e nem mesmo a que título, pois a sucessão se efetivará em qualquer caso, não ficando restrita a determinadas situações.

No tocante a responsabilidade dos envolvidos, sucessor e sucedido, viu-se que o sucessor tem sua responsabilização atribuída em virtude de lei. Assim, ele será responsabilizado por todos os débitos trabalhistas ligados à atividade econômica organizada, por ele adquirida, independendo a sua responsabilização da data em que ocorreu a sucessão, de tal forma ele responderá pelos créditos, até mesmo, daquele empregado que nunca prestou serviço para ele diretamente. De tal forma, o sucessor é responsável até mesmo pelos créditos daquele trabalhador que teve seu contrato rescindido antes de ocorrer o evento da sucessão.

Com relação ao sucedido foi visto que pelo menos de início não teria responsabilidade algum após a sucessão. Mas, deixou-se claro que a lei trabalhista tem por fim a proteção dos contratos de trabalho e também dos créditos dos trabalhadores. Portanto ela não visa proteger a figura do sucedido, em virtude disso, a sua responsabilização não foi excluída pela lei em nenhum momento. Ainda, ficou evidenciado no decorrer do trabalho que a responsabilização do sucedido será imperativa obviamente nos caso de ocorrência de fraude, e também pela simples perda de garantia pelos empregados, ou seja, quando a empresa sucessora não possuir condições de fazer frente a todos os créditos dos trabalhadores já é possível à responsabilização do sucedido.

Destacou-se que a responsabilização do sucedido se dá em caráter excepcional, quando as garantias dos trabalhadores restarem comprometidas pela sucessão. Salientou-se ainda que eventual responsabilização do sucedido deve se dar na forma subsidiária e não solidária.

No presente estudo ainda preocupou-se em analisar situação muito corriqueira no mundo empresarial, que é a divisão de responsabilidade pelos débitos da empresa, objeto da transferência, por meio de contratos. Sobre tal situação analisou-se que tais cláusulas são válidas, mas sofre a seguinte ressalva, elas não têm eficácia perante a justiça laboral, ou seja, 
estas cláusulas limitadores de responsabilidades não podem ser opostas aos direitos dos trabalhadores, como no caso da sucessão. Afinal, tais direitos decorrem de normas de ordem pública, as quais obviamente devem preponderar sobre normas de natureza contratual.

Com relação às privatizações, foi visto que se referem ao processo por meio do qual o poder público transfere para o setor privado atividade econômica por ele exercida. Tal transferência se dá por meio de contratos administrativos, os quais são precedidos de um processo de licitação.

Os citados contratos administrativos, apesar de não se amoldarem aos contratos disciplinados pelo direito civil, não deixam de ter natureza contratual, pois em suma, se tratam de um acordo de vontades, o qual gera direitos e obrigações recíprocas entre as partes.

Foi destacado quais seriam os meios de licitação utilizados para o processo de privatização. Observou-se que a lei disciplinadora do Programa Nacional de Desestatização trouxe a possibilidade de as principais modalidades de desestatização se darem por meio de leilão.

Em decorrência de citada possibilidade o leilão é a modalidade mais usada nas desestatizações, mas destacou-se que tal leilão difere do previsto pela Lei n. 8.666/93, pois sua aplicação em razão da Lei n. 9.491/97 se dá com prévia habilitação dos candidatos e ainda com garantia das propostas apresentadas, o que se faz necessário frente aos interesses objeto de tal procedimento.

No tocante ao caso especifico das privatizações, buscou-se analisar a validade das cláusulas estabelecidas nos contratos que efetivam a transferência da atividade econômica do poder público para o setor privado, as quais prevêem que o poder público fica responsável pelos créditos trabalhista dos empregados até o momento da transferência. Tais cláusulas são usadas para que o poder público consiga uma melhor oferta pela a atividade a ser transferida.

Entretanto, conforme a análise realizada pelo presente estudo, tais cláusulas não tem validade alguma perante os empregados, sendo que sua eficácia se restringe à relação travada entre o poder público e o adquirente. 
Deixou-se claro que a exclusão da eficácia de tais cláusulas perante os direitos dos trabalhadores não caracteriza sobreposição de interesses individuais sobre o público. Neste sentido ficou demonstrado que a proteção ao trabalho é fundamento do Estado brasileiro, conforme dispõe a Carta Magna em seu artigo 170. Negando a existência de tal sobreposição, foi defendido que a sucessão advém de norma de ordem pública, enquanto a limitação da responsabilidade dos sucessores advém de contratos. Por fim, destacou-se que o legislador, em nenhum momento preocupou-se em positivar suposto 'interesse público', em especial firmou-se o caso do PND, que advém de lei muito mais recente do que a CLT, e mesmo assim naquela norma não trouxe a previsão da pretendida limitação de responsabilidade do sucessor nas privatizações.

Conclui-se finalmente que a sucessão de empregadores é um instituto que visa trazer segurança aos empregados, prevendo a continuidade dos contratos, independentemente das mudanças sofridas pela empresa, e, ainda, vinculando os créditos dos empregados aos bens, estrutura econômico-produtiva da empresa, de forma a dar-lhes maior garantia de solvência. E ainda, restou claro que para a caracterização da sucessão de empregadores será irrelevante qual a mudança que venha a sofrer a empresa, qual o meio de efetivação de tal mudança, e também, será insignificante as pessoas envolvidas, ou seja, a natureza jurídica da sucessora e da sucedida.

\section{Referências}

BARROS, Alice Monteiro de. Curso de direito do trabalho. 2. ed. São Paulo: LTr, 2006.

CARRION, Valentin. Comentários à consolidação das leis do trabalho. 26. ed. atual. ampl. São Paulo: Saraiva, 2001.

CARVALHO FILHO, José dos Santos. Manual de direito administrativo. 12. ed. Rio de Janeiro: Lúmen Júris, 2005.

COELHO, Fábio Ulhoa. Curso de direito comercial: de acordo com o novo Código Civil e alterações da LSA. 7. ed. rev. e atual. São Paulo: Saraiva, 2003. v. 1.

DELGADO, Maurício Godinho. Introdução ao direito do trabalho: relações de trabalho e relações de emprego. 3. ed. rev. e ampl. São Paulo: LTr, 2001. 
. Curso de direito do trabalho. 4. ed. São Paulo: LTr, 2005.

DERANI, Cristiane. Privatização e serviços públicos: as ações do estado na produção econômica. São Paulo: Max Limonad, 2002.

DI PIETRO, Maria Sylvia Zanella. Direito administrativo. 17. ed. São Paulo: Atlas, 2004.

FIGUEIREDO, Lúcia Valle Figueiredo. Curso de direito administrativo. 7. ed. rev. atual. e ampl. São Paulo: Malheiros, 2004.

GARCIA, Gustavo Felipe Barbosa. Curso de direito do trabalho. São Paulo: Método, 2007.

JORGE NETO, Francisco Ferreira. Sucessão trabalhista: privatização e reestruturação do mercado financeiro. São Paulo: LTr, 2001.

MAGANO, Octavio Bueno. ABC do direito do trabalho. São Paulo: Revista dos Tribunais, 1998.

MARTINS, Sergio Pinto. Direito do trabalho. 16. ed. atual. São Paulo: Atlas, 2002.

. Comentário à CLT. 10. ed. São Paulo: Atlas, 2006.

MEDAUAR, Odete. Direito administrativo moderno. 8. ed. rev. e atual. São Paulo: Revista dos Tribunais, 2004.

MEIRELLES, Hely Lopes. Direito Administrativo. 25. ed. São Paulo: Malheiros, 2000.

MELLO, Celso Antônio Bandeira de. Curso de direito administrativo. 18. ed. rev. e atual. São Paulo: Malheiros, 2005.

MUKAl, Toshio. Concessões, permissões e privatizações de serviços públicos. 4. ed. São Paulo: Saraiva. 2002.

NASCIMENTO, Amauri Mascaro. Curso de direito do trabalho. 17. ed. rev. e atual. São Paulo: Saraiva, 2001.

RODRIGUES, Américo Plá. Princípios de direito do trabalho. 3. ed. atual. São Paulo: LTr, 2000.

RUSSOMANO, Mozart Victor. Curso de direito do trabalho. 9. ed. Curitiba: Juruá, 2005. 
SOUTO, Marcos Juruena Villela. Direito administrativo regulatório. Rio de Janeiro: Lúmen Júris, 2002.

SÜSSEKIND, Arnaldo et al. Instituições de direito do trabalho. 21. ed. atual. São Paulo: LTr, 2004.

TRT9, Jurisprudência, Curitiba, 2007. Disponível em: <www.trt9.gov.br>.

TRT02, Jurisprudência, São Paulo, 2007. Disponível em: <www.trt02.gov.br>.

TRT6, Jurisprudência, Recife, 2007. Disponível em: <www.trt6.gov.br>.

TST, Jurisprudência, Brasília, 2007. Disponível em: <www.tst.gov.br>. 
